\title{
Prevention and early intervention for borderline personality disorder: current status and recent evidence
}

\author{
Andrew M. Chanen and Louise McCutcheon
}

\section{Summary}

Borderline personality disorder (BPD) is a leading candidate for developing empirically based prevention and early intervention programmes because it is common in clinical practice, it is among the most functionally disabling of all mental disorders, it is often associated with help-seeking, and it has been shown to respond to intervention, even in those with established disorder. Moreover, it can be reliably diagnosed in its early stages and it demarcates a group with high levels of current and future morbidity and mortality.
Data also suggest considerable flexibility and malleability of BPD traits in youth, making this a key developmental period during which to intervene. Novel indicated prevention and early intervention programmes have shown that BPD in young people responds to intervention. Further work is required to develop appropriate universal and selective preventive interventions.

\section{Declaration of interest}

None.
Borderline personality disorder (BPD) is a severe mental disorder that is characterised by a pervasive pattern of impulsivity, emotional instability, interpersonal dysfunction and disturbed self-image. ${ }^{1}$ It affects $0.7-2.7 \%$ of the general adult population, ${ }^{2,3}$ $9.3-22.5 \%$ of people receiving psychiatric out-patient treatment, and in some settings over $40 \%$ of in-patients. ${ }^{4}$ The outcome of this disorder in adulthood is now reliably characterised by attenuation of diagnostic criteria over time, but with severe and continuing functional disability across a broad range of domains that is comparable to or greater than that associated with many mental state disorders. ${ }^{5,6}$ People with the disorder also have continuing high rates of health service use, ${ }^{7,8}$ and a suicide rate of around $8 \% .{ }^{9}$ Although effective interventions exist for adults, ${ }^{10-12}$ the overall outcomes from such interventions are modest and their availability is limited.

\section{Disorder in young people}

Despite long-standing general agreement that personality disorders have their roots in childhood and adolescence, ${ }^{13}$ diagnosing these disorders prior to age 18 years has been more controversial than diagnosing them in adults; ${ }^{14}$ however, this is no longer justified. ${ }^{15}$ Borderline personality disorder is increasingly seen as a lifespan developmental disorder, ${ }^{16}$ which is just as reliable and valid in adolescence as it is in adulthood, ${ }^{17,18}$ is not reducible to Axis I diagnoses, ${ }^{19}$ and can be identified in day-to-day clinical practice. ${ }^{20}$ When the diagnosis is applied, BPD occurs in approximately $3 \%$ of community-dwelling teenagers and young people. ${ }^{21,22}$ Indeed, BPD might be better considered as a disorder of younger people, with a rise in prevalence from puberty and a steady decline with each decade from young adulthood. ${ }^{23-25}$ Limited data suggest that BPD occurs in up to $22 \%$ of adolescents and young adults receiving out-patient treatment. ${ }^{20,26}$ Borderline personality disorder (or its dimensional representations) in young people demarcates a group with high morbidity and a particularly poor outcome. This disorder uniquely and independently predicts current psychopathology, general functioning, peer relationships, self-care and family and relationship functioning. ${ }^{19}$ It also uniquely predicts poor outcomes up to two decades into the future, such as a future BPD diagnosis, increased risk of Axis I disorders (especially substance use and mood disorders), interpersonal problems, distress and reduced quality of life. ${ }^{27-29}$

\section{Prevention and early intervention}

The above data suggest that BPD is a leading candidate for developing empirically based prevention and early intervention programmes because it is common in clinical practice, it is among the most functionally disabling of all mental disorders, it is often associated with help-seeking (cf. schizotypal or antisocial personality disorder), ${ }^{30}$ and it has been shown to respond to intervention even in those with established disorder. Moreover, BPD can be reliably diagnosed in its early stages and it demarcates a group with high levels of current and future morbidity and mortality. Data also suggest considerable flexibility and malleability of BPD traits in youth, ${ }^{31}$ making this a key developmental period during which to intervene, and adolescent $\mathrm{BPD}$ features have been shown to respond to intervention. ${ }^{32,33}$

\section{Aims of prevention and early intervention}

Prevention and early intervention for BPD should primarily aim to alter the life-course trajectory of young people with borderline personality pathology by attenuating or averting associated adverse outcomes and promoting more adaptive developmental pathways. It should not be narrowly focused on the diagnostic features of BPD, as these naturally attenuate over time. Antisocial personality disorder provides a useful model for such purposes. There is a remarkable amount of information about childhoodonset and adolescent-onset conduct disorder and the developmental pathways leading to antisocial personality disorder, along with associated outcomes such as substance misuse, mental disorders and poor physical health. ${ }^{34}$ These data logically give rise to potential 'universal', 'selective' and 'indicated' preventive interventions, ${ }^{35}$ along with early intervention for the established phenotype. ${ }^{36,37}$ Although the time course and form of early manifestations of BPD are likely to differ from those of antisocial personality disorder, the two disorders have substantial phenotypic overlap, and similar objectives might be realised for BPD 
through identifying appropriate risk factors and antecedents for intervention.

\section{Risk factors}

Findings from prospective longitudinal studies of community samples and studies of young people with borderline pathology suggest a variety of genetic, neurobiological, psychopathological and environmental risk factors for BPD. A fundamental drawback of these data is that their specificity for the disorder appears to be limited.

Heritability estimates for BPD (or its dimensional representations) are around $40 \% .^{38-40}$ No specific gene has been identified as causative of BPD and findings from molecular genetic studies have been difficult to replicate. ${ }^{41}$ Evidence supports both gene-environment interaction and correlation in the development of $\mathrm{BPD}^{42}$ This means that individuals with a 'sensitive' genotype are at greater risk of the disorder in the presence of a predisposing environment. Furthermore, the genes that influence BPD features also increase the likelihood of being exposed to certain adverse life events. So-called comorbidity of BPD with other disorders might also be due to gene-environment correlation: for example, the genetic and environmental correlations between adult BPD traits and adult attention-deficit hyperactivity disorder (ADHD) symptoms support a shared aetiology. ${ }^{40}$

Frontolimbic network abnormalities have been associated with many of the features of BPD in adults, ${ }^{1}$ but it is unclear whether these findings are a cause, an effect or an epiphenomenon of the disorder. ${ }^{43}$ In order to be implicated in the aetiology such abnormalities should be present early in the course of the disorder. Thus far, three structural neuroimaging studies have compared adolescents with BPD with healthy control participants. ${ }^{43-45}$ They found reduced orbitofrontal cortex and anterior cingulate cortex volumes, ${ }^{43-46}$ but not reduced hippocampal or amygdala volumes (which have been widely reported in adult BPD). ${ }^{47}$ One study also included a non-BPD clinical comparison group and found similar changes in this group (compared with healthy control participants) ${ }^{44}$ suggesting that the findings might not be specific to BPD. Although hypothalamic-pituitary-adrenocortical (HPA) axis findings in BPD have been contradictory, ${ }^{48}$ individuals with this disorder have an attenuated cortisol response to acute stress compared with a healthy control group, ${ }^{49}$ and this has also been found in adolescents who self-harm. ${ }^{50}$ More numerous parasuicidal behaviours in adolescents with first-presentation BPD were associated with increased pituitary volumes, ${ }^{51}$ suggesting greater activation of the HPA axis. Therefore, it is possible that prolonged activation of the HPA axis in individuals with chronic stress might induce HPA axis hyporesponsiveness, providing a possible developmental pathway to BPD. Adolescent patients with BPD show stronger orienting to negative emotional stimuli than healthy comparison participants but this does not appear to be specific to the disorder. ${ }^{52}$ Adolescent borderline pathology has also been linked to an inability to disengage attention from negative facial expressions during attentional maintenance when in a negative mood. ${ }^{53}$ However, one study of young people (15-24 years old) with BPD showed no evidence of heightened sensitivity to emotional facial expressions, compared with a community control group. ${ }^{54}$ Young people with borderline pathology have been found to have an impaired capacity to differentiate and integrate the perspective of the self with the perspectives of others (social perspective coordination), ${ }^{55}$ along with impairments in theory of mind (mentalising) due to overinterpretive mental state reasoning, rather than the reduction or loss of theory of mind capacity per se. ${ }^{56}$ They have also been found to have a preference for immediate gratification and a tendency to discount longer-term rewards, which might be related to trait impulsivity. ${ }^{57}$

Taken together, these findings provide interesting clues but no clear and consistent target for intervention. Prospective, longitudinal data are more consistent in demonstrating that a range of childhood and parental demographic characteristics, adverse childhood experiences, early relational difficulties, parental problems and forms of maladaptive parenting are risk factors for adolescent and adult BPD.

Although there is a strong association between BPD and adverse childhood experiences, ${ }^{58}$ the precise aetiological role of childhood adversity remains unclear because putative risk factors such as childhood abuse, adverse familial environment and a family history of psychopathology are highly intercorrelated. ${ }^{59}$ One study has demonstrated that the association between life events and BPD features can be explained by shared genetic influences, causal effects and an interaction between genes and environment, depending on the type of life event. ${ }^{42}$ Specific data on prospectively assessed risk factors for BPD are still insufficient, with the Children in the Community (CIC) study being the only study to have published prospective risk factors over multiple waves from childhood through to adulthood. ${ }^{27} \mathrm{~A}$ series of CIC publications report childhood abuse or neglect, childhood and parental demographic characteristics, maladaptive parenting and maladaptive school experiences as risk factors for adolescent and adult personality disorder. ${ }^{27,60}$ Prospective longitudinal data have found that childhood physical abuse, sexual abuse and neglect, ${ }^{61}$ along with low socioeconomic status of the family of origin, ${ }^{62}$ are independently associated with elevated features of BPD up to two decades later. Also, maternal inconsistency in child-rearing in the presence of high maternal overinvolvement, ${ }^{63}$ maladaptive parenting behaviour present during the child-rearing years, ${ }^{64}$ early separations of offspring from their mothers before age 5 years, ${ }^{65}$ and early relational experiences including attachment disorganisation and maltreatment, maternal hostility and boundary dissolution, family disruption related to father's presence and family life stress, ${ }^{66}$ all predict elevations in BPD features $2-30$ years later.

\section{Precursor signs and symptoms}

Prospective longitudinal data indicate that certain temperamental characteristics and early-onset mental state or behavioural problems that are analogous to characteristics of BPD are precursors to the emergence of the BPD phenotype but do not predict its onset with certainty. These include ADHD, oppositional defiant disorder, conduct disorder, substance use, depression and self-harm, along with the actual features of BPD. However, it is technically imprecise to refer to many of these phenomena as 'risk factors, ${ }^{, 67}$ as these same phenomena are later used to define personality disorder. Eaton et al refer to the signs and symptoms from a diagnostic cluster that precede a disorder but do not predict its onset with certainty as 'precursor signs and symptoms. ${ }^{68}$

Maternal reports of childhood temperament are related to $\mathrm{BPD}$ in adolescence or adulthood, up to 30 years later. ${ }^{65,66}$ Substance use disorders during adolescence - particularly alcohol use disorders - also specifically predict young adult BPD, ${ }^{69,70}$ and there are strong prospective data that disturbances in attention, emotional regulation and behaviour, especially the disruptive behaviour disorders (conduct disorder, oppositional defiant disorder, ADHD) in childhood or adolescence are independent predictors of young adult BPD. ${ }^{66,71,72}$ Moreover, in one study 
the rate of growth in ADHD scores from age 10 to 13 years and the rate of growth in oppositional defiant disorder scores from age 8 to 10 years uniquely predicted higher BPD symptoms at age 14 years, suggesting that for adolescent BPD symptoms, difficulties with emotion regulation and relationships might precede problems with impulse control. $^{71}$

Self-harm is a core feature of BPD, ${ }^{1}$ and retrospective reports from adults with the disorder indicate childhood onset of self-harm in more than $30 \%$ and adolescent onset in another $30 \%{ }^{73}$ However, it is surprisingly underresearched as a potential precursor to BPD. Although self-harm is relatively common among adolescents and young adults, ${ }^{74}$ and is associated with a range of clinical syndromes, there is evidence that repetitive self-harm (which is less frequent) might differ from occasional self-harm. ${ }^{75}$ Borderline personality disorder can be diagnosed in the majority of adolescent girls receiving in-patient treatment for self-harm, ${ }^{76}$ and the likelihood of meeting the diagnosis of BPD is greater in adolescents endorsing both self-harm and suicide attempts compared with individuals reporting self-harm or suicide attempts alone. ${ }^{77}$ Also, the number of BPD criteria met is predictive of whether or not an adolescent has engaged in self-harm or attempted suicide. ${ }^{78}$

There is now clear evidence that dimensional representations of BPD features have similar stability in adolescence and adulthood. ${ }^{17}$ Evidence is emerging that the underlying dimensions of these features (conceptualised as impulsivity, negative affectivity and interpersonal aggression) are also stable in children. ${ }^{79,80}$ Only the CIC has specifically measured childhood or adolescent features of personality disorder as a predictor of later personality disorder over multiple assessments from childhood to adulthood. ${ }^{27}$ Personality disorder symptoms in childhood or adolescence were the strongest long-term predictors, over and above disruptive behaviour disorders and depressive symptoms, of later DSM-IV cluster A, B or C disorders. ${ }^{27,81-83}$ Overall, the CIC data support a normative increase in BPD traits after puberty, perhaps bringing the problems associated with this disorder to clinical attention. As this wanes in early adulthood, partly due to maturational or socialisation processes, ${ }^{27}$ a group is revealed that is increasingly deviant compared with their peers, ${ }^{84}$ and perhaps conforms more to the 'adult' BPD phenotype. This suggests that young people displaying BPD features are a major group from which the adult phenotype arises. In short, signs and symptoms might appear from childhood through to adolescence that resemble aspects of the BPD phenotype and presage its later appearance in adolescence or emerging adulthood. Certain early temperamental and personality features, internalising and externalising psychopathology and specific BPD criteria are all candidate precursor signs and symptoms. However, more work needs to be done to gain a better understanding of the part these factors play in the developmental pathways to BPD and to increase their specificity for the disorder.

\section{What form should intervention take?}

Stand-alone universal (whole population) prevention of BPD is not currently feasible because the condition is not sufficiently prevalent to justify whole-population approaches, and it is unclear what form of intervention would be appropriate. Similarly, selective prevention (targeting those with risk factors for BPD) is currently impractical because many of the risk factors (particularly environmental factors) more commonly lead to, or are associated with, outcomes other than BPD (multifinality). ${ }^{85}$ This should not diminish the importance of intervention for some risk factors (e.g. child abuse and neglect) as primary objectives because they are undesirable, immoral or unlawful. However, many factors such as poverty require major social and political change and are unlikely to have a major impact on BPD prevention in the near future. Also, it is difficult to design studies with adequate statistical power to demonstrate the efficacy or effectiveness of universal and selective prevention. ${ }^{86}$ Some of these problems would be overcome if current universal and selective programmes (e.g. parent training programmes) were to measure multiple syndromes as outcomes, and the above data constitute a strong case for including BPD as one of these syndromes.

The data reviewed above suggest that 'indicated prevention' is currently the 'best bet' for prevention of BPD. ${ }^{17}$ This targets individuals displaying precursor (early) signs and symptoms of the disorder. Although the BPD phenotype is not clearly identifiable in children, its underlying dimensions can be measured, appear to be relatively stable and could be directly targeted. Moreover, typical child and adolescent psychopathology (e.g. disruptive behaviour disorders, self-harm, substance use and depressive disorders) might additionally be regarded as targets for indicated prevention of BPD, rather than separate domains of psychopathology that might then be renamed in adulthood. Two programmes, described below, have been developed that directly target subsyndromal borderline pathology in adolescents, ${ }^{32,33,87}$ while concurrently targeting syndromal BPD.

\section{Early detection and intervention}

Early detection and intervention for BPD are now justified and practical in adolescence and emerging adulthood, ${ }^{15,20}$ and novel early intervention programmes have been developed and researched in Australia and The Netherlands. ${ }^{32,33,87}$ Such programmes should be differentiated from conventional BPD treatment programmes that are applied to individuals who have established, complex and severe disorder but happen to be less than 18 years old. Intervention for this latter group should now be considered part of routine clinical practice in adolescent mental health. ${ }^{15}$

\section{Principles of early intervention}

The Australian Helping Young People Early (HYPE) and Dutch Emotion Regulation Training (ERT) treatment programmes have several features in common. ${ }^{33,87}$ They have broad inclusion criteria, with limited exclusions for co-occurring psychopathology (which is common in BPD). They view BPD dimensionally, combining subsyndromal (indicated prevention) and syndromal (early intervention) disorder. Borderline and other personality disorders are carefully diagnosed, often supported by semistructured interview. Both HYPE and ERT are time-limited, being 16-24 and 17 sessions long respectively. Both have adapted interventions designed for adults with BPD to make them developmentally suitable. The HYPE programme uses cognitiveanalytic therapy, ${ }^{88}$ whereas ERT uses Systems Training for Emotional Predictability and Problem Solving (STEPPS). ${ }^{89}$ The major difference between these programmes is that ERT is delivered in a group format as an adjunct to treatment as usual, whereas HYPE employs a comprehensive, team-based, integrated intervention. In a randomised controlled trial, ERT plus treatment as usual was not substantially different from treatment as usual alone. ${ }^{33}$ In contrast, a quasi-experimental comparison of the HYPE intervention and treatment as usual found that HYPE achieved faster rates of improvement in internalising and externalising psychopathology and lower levels of psychopathology at 2-year follow-up. ${ }^{90}$ This suggests that some or all of the 
elements of a team-based, integrated intervention might be important for early intervention, and matches clinical experience working with this population. In HYPE, these elements include:

(a) assertive, 'psychologically informed' case management integrated with the delivery of individual psychotherapy;

(b) active engagement of families or carers, with psychoeducation and time-limited family intervention, using the same model as individual psychotherapy;

(c) general psychiatric care by the same team, with specific assessment and treatment of co-occurring psychiatric syndromes (comorbidity), including the use of pharmacotherapy, where indicated for such syndromes;

(d) capacity for outreach care in the community, with flexible timing and location of intervention;

(e) crisis team and in-patient care, with a clear model of brief and goal-directed in-patient care;

(f) access to a psychosocial recovery programme (shared with other programmes at Orygen Youth Health);

(g) individual and group supervision of staff;

(h) a quality assurance programme.

\section{Remaining barriers and potential risks}

Despite evidence of sufficient reliability and validity for the BPD diagnosis in young people, stigma is a lingering barrier to its early diagnosis in day-to-day clinical practice. Borderline personality disorder is highly stigmatised among professionals, ${ }^{91}$ and it is also associated with patient 'self-stigma. ${ }^{92}$ This fuels the perception that the diagnosis is 'controversial, ${ }^{14}$ and experience suggests that many clinicians will deliberately avoid using the diagnosis in young people with the aim of 'protecting' individuals from harsh and/or discriminatory practices. Although concerns about stigma are genuine and the response is well intentioned, this practice runs the risk of perpetuating negative stereotypes, reducing the prospect of applying specific beneficial interventions for the problems associated with BPD and increasing the likelihood of inappropriate diagnoses and interventions and iatrogenic harm (such as polypharmacy). The National Institute for Health and Clinical Excellence (NICE) guideline for BPD supports the diagnosis of this disorder in adolescents, ${ }^{15}$ and the forthcoming revisions of the ICD and DSM classification systems are both proposing to remove age-related caveats on the diagnosis of personality disorders. ${ }^{93,94}$ Moreover, the ICD (and possibly the DSM) will include the identification of subthreshold personality pathology. These innovations foster not only the early diagnosis of BPD but also the identification of subthreshold disorder, supporting the aims of indicated prevention and early intervention. However, this will bring into the clinical realm young people (and adults) who might once have been considered 'colourful', and potential benefits are accompanied by potential risks associated with 'medicalising' common problems - risks that are not confined to the field of personality disorders.

\section{Future perspectives}

Borderline personality disorder should now be seen as a lifespan developmental disorder with substantial ramifications across subsequent decades. Consequently, intervention at any stage should aim to alter the life-course trajectory of the disorder, not just its diagnostic features. There is now sufficient evidence to support diagnosing and treating BPD when it first appears as routine clinical practice. This has already been adopted by the NICE guideline for BPD and it is likely to be supported by the ICD-11 and DSM-5. There are also data showing that targeting subsyndromal borderline pathology through indicated prevention is a promising approach and that the benefits of intervention appear to outweigh the risks. However, this approach requires further development and evaluation over longer periods in order to ensure that there are no significant 'downstream' adverse effects.

Indicated prevention and early intervention also offer a unique platform for investigating BPD earlier in its developmental course, where duration of illness factors that complicate the psychopathology and neurobiology of the disorder can be minimised. This might make more sense of the confusing array of biological and psychopathological research findings for the disorder. In the future a more detailed understanding of risk factors, precursors, pathways and mechanisms for the development of BPD might enable the development of universal or selective preventive approaches, but these are likely to require the joint effort of research groups aiming to prevent the range of major mental disorders. 'Clinical staging' for BPD, ${ }^{95}$ which is analogous to disease staging in general medicine, offers a potential integrating framework for selecting appropriate interventions and predicting outcome. A key implication of such an approach is that treatment needs will differ by phase or stage of disorder, with the possibility that interventions might be more benign and/or effective in earlier phases.

Andrew M. Chanen, MBBS, MPM, PhD, FRANZCP, Louise Mccutcheon, DPsych, MAPS, Orygen Youth Health Research Centre, Centre for Youth Mental Health, University of Melbourne, and Orygen Youth Health Clinical Program, Northwestern Mental Health, Melbourne, Australia

Correspondence: Associate Professor Andrew M. Chanen, Orygen Youth Health Research Centre, Locked Bag 10, Parkville, Victoria 3052, Australia. Email: achanen@unimelb.edu.au

\section{Funding}

The Orygen Youth Health Research Centre is funded by an unrestricted philanthropic grant from the Colonial Foundation, Melbourne, Australia.

\section{References}

1 Leichsenring F, Leibing E, Kruse J, New AS, Leweke F. Borderline personality disorder. Lancet 2011; 377: 74-84.

2 Coid J, Yang M, Tyrer $\mathrm{P}$, Roberts A, Ullrich S. Prevalence and correlates of personality disorder in Great Britain. Br J Psychiatry 2006; 188: 423-31.

3 Trull TJ, Jahng S, Tomko RL, Wood PK, Sher KJ. Revised NESARC Personality disorder diagnoses: gender, prevalence, and comorbidity with substance dependence disorders. J Pers Disord 2010; 24: 412-26.

4 Zimmerman M, Chelminski I, Young D. The frequency of personality disorders in psychiatric patients. Psychiatr Clin North Am 2008; 31: 405-20, vi.

5 Gunderson JG, Stout RL, McGlashan TH, Shea MT, Morey LC, Grilo CM, et al. Ten-year course of borderline personality disorder: psychopathology and function from the collaborative longitudinal personality disorders study. Arch Gen Psychiatry 2011; 68: 827-37.

6 Zanarini MC, Frankenburg FR, Reich DB, Fitzmaurice G. The 10-year course of psychosocial functioning among patients with borderline personality disorder and axis II comparison subjects. Acta Psychiatr Scand 2010; 122: 103-9.

7 Horz S, Zanarini MC, Frankenburg FR, Reich DB, Fitzmaurice G. Ten-year use of mental health services by patients with borderline personality disorder and with other axis II disorders. Psychiatr Serv 2010; 61: 612-6.

8 Sansone RA, Farukhi S, Wiederman MW. Utilization of primary care physicians in borderline personality. Gen Hosp Psychiatry 2011; 33: 343-6.

9 Pompili M, Girardi P, Ruberto A, Tatarelli R. Suicide in borderline personality disorder: a meta-analysis. Nord J Psychiatry 2005; 59: 319-24.

10 Bateman A, Fonagy P. Randomized controlled trial of outpatient mentalization-based treatment versus structured clinical management for borderline personality disorder. Am J Psychiatry 2009; 166: 1355-64. 
11 Linehan MM, Comtois KA, Murray AM, Brown MZ, Gallop RJ, Heard HL, et al Two-year randomized controlled trial and follow-up of dialectical behavior therapy vs therapy by experts for suicidal behaviors and borderline personality disorder. Arch Gen Psychiatry 2006; 63: 757-66.

12 Giesen-Bloo J, van Dyck R, Spinhoven P, van Tilburg W, Dirksen C, van Asselt $T$, et al. Outpatient psychotherapy for borderline personality disorder: randomized trial of schema-focused therapy vs transferencefocused psychotherapy. Arch Gen Psychiatry 2006; 63: 649-58.

13 American Psychiatric Association. Diagnostic and Statistical Manual of Mental Disorders (3rd edn) (DSM-III). APA, 1980.

14 Chanen AM, McCutcheon LK. Personality disorder in adolescence: the diagnosis that dare not speak its name. Personal Ment Health 2008; 2 35-41.

15 National Collaborating Centre for Mental Health. Borderline Personality Disorder: Treatment and Management (Clinical Guideline CG78). National Institute for Health and Clinical Excellence, 2009

16 Tackett JL, Balsis S, Oltmanns TF, Krueger RF. A unifying perspective on personality pathology across the life span: developmental considerations for the fifth edition of the Diagnostic and Statistical Manual of Mental Disorders. Dev Psychopathol 2009; 21: 687-713.

17 Chanen AM, Jovev M, McCutcheon L, Jackson HJ, McGorry PD. Borderline personality disorder in young people and the prospects for prevention and early intervention. Curr Psychiatry Rev 2008; 4: 48-57.

18 Miller AL, Muehlenkamp JJ, Jacobson CM. Fact or fiction: diagnosing borderline personality disorder in adolescents. Clin Psychol Rev 2008; 28 : 969-81

19 Chanen AM, Jovev M, Jackson HJ. Adaptive functioning and psychiatric symptoms in adolescents with borderline personality disorder. J Clin Psychiatry 2007; 68: 297-306.

20 Chanen AM, Jovev M, Djaja D, McDougall E, Yuen HP, Rawlings D, et al. Screening for borderline personality disorder in outpatient youth. J Pers Disord 2008; 22: 353-64.

21 Bernstein DP, Cohen P, Velez CN, Schwab-Stone M, Siever L, Shinsato L. Prevalence and stability of the DSM-III-R personality disorders in a community-based survey of adolescents. Am J Psychiatry 1993; 150 1237-43.

22 Moran P, Coffey C, Mann A, Carlin JB, Patton GC. Personality and substance use disorders in young adults. Br J Psychiatry 2006; 188: 374-9.

23 Ullrich S, Coid J. The age distribution of self-reported personality disorder traits in a household population. J Pers Disord 2009; 23: 187-200.

24 Johnson JG, Cohen P, Kasen S, Skodol AE, Hamagami F, Brook JS. Age-related change in personality disorder trait levels between early adolescence and adulthood: a community-based longitudinal investigation. Acta Psychiatr Scand 2000; 102: 265-75.

25 Samuels J, Eaton WW, Bienvenu III OJ, Brown CH, Costa Jr PT, Nestadt G. Prevalence and correlates of personality disorders in a community sample. Br J Psychiatry 2002; 180: 536-42.

26 Chanen AM, Jackson HJ, McGorry PD, Allott KA, Clarkson V, Yuen HP. Two-year stability of personality disorder in older adolescent outpatients. J Pers Disord 2004; 18: 526-41.

27 Cohen P, Crawford TN, Johnson JG, Kasen S. The children in the community study of developmental course of personality disorder. J Pers Disord 2005; 19: 466-86.

28 Crawford TN, Cohen P, First MB, Skodol AE, Johnson JG, Kasen S. Comorbid Axis I and Axis II disorders in early adolescence: prognosis 20 years later. Arch Gen Psychiatry 2008; 65: 641-8.

29 Winograd G, Cohen P, Chen H. Adolescent borderline symptoms in the community: prognosis for functioning over 20 years. J Child Psychol Psychiatry 2008; 49: 933-41.

30 Tyrer $\mathrm{P}$, Mitchard $\mathrm{S}$, Methuen $\mathrm{C}$, Ranger $\mathrm{M}$. Treatment rejecting and treatment seeking personality disorders: Type R and Type S. J Pers Disord 2003; 17: 263-8

31 Lenzenweger MF, Castro DD. Predicting change in borderline personality: using neurobehavioral systems indicators within an individual growth curve framework. Dev Psychopathol 2005; 17: 1207-37.

32 Chanen AM, Jackson HJ, McCutcheon LK, Jovev M, Dudgeon P, Yuen HP, et al. Early intervention for adolescents with borderline personality disorder using cognitive analytic therapy: randomised controlled trial. Br J Psychiatry 2008; 193: $477-84$.

33 Schuppert H, Giesen-Bloo J, van Gemert T, Wiersema H, Minderaa R, Emmelkamp $\mathrm{P}$, et al. Effectiveness of an emotion regulation group training for adolescents - a randomized controlled pilot study. Clin Psychol Psychother 2009; 16: 467-78.
34 Moffitt TE, Arseneault L, Jaffee SR, Kim-Cohen J, Koenen KC, Odgers CL, et al. Research review: DSM-V conduct disorder: research needs for an evidence base. J Child Psychol Psychiatry 2008; 49: 3-33.

35 Mrazek PJ, Haggerty RJ. Reducing Risks For Mental Disorders: Frontiers For Preventive Intervention Research. National Academy Press, 1994.

36 Woolfenden SR, Williams K, Peat JK. Family and parenting interventions for conduct disorder and delinquency: a meta-analysis of randomised controlled trials. Arch Dis Child 2002; 86: 251-6.

37 Weisz JR, Hawley KM, Doss AJ. Empirically tested psychotherapies for youth internalizing and externalizing problems and disorders. Child Adolesc Psychiatr Clin N Am 2004; 13: 729-815, v-vi.

38 Distel MA, Trull TJ, Derom CA, Thiery EW, Grimmer MA, Martin NG, et al. Heritability of borderline personality disorder features is similar across three countries. Psychol Med 2008; 38: 1219-29.

39 Kendler KS, Aggen SH, Czajkowski N, Roysamb E, Tambs K, Torgersen S, et al. The structure of genetic and environmental risk factors for DSM-IV personality disorders: a multivariate twin study. Arch Gen Psychiatry 2008; 65: 1438-46.

40 Distel MA, Carlier A, Middeldorp CM, Derom CA, Lubke GH, Boomsma DI. Borderline personality traits and adult attention-deficit hyperactivity disorder symptoms: a genetic analysis of comorbidity. Am J Med Genet 2011; 156B: 817-21.

41 Chanen AM, Kaess M. Developmental pathways toward borderline personality disorder. Curr Psychiatry Rep 2012; 14: 45-53.

42 Distel MA, Middeldorp CM, Trull TJ, Derom CA, Willemsen G, Boomsma DI. Life events and borderline personality features: the influence of geneenvironment interaction and gene-environment correlation. Psychol Med 2011; 41: 849-60.

43 Chanen AM, Velakoulis D, Carison K, Gaunson K, Wood SJ, Yücel M, et al. Orbitofrontal, amygdala and hippocampal volumes in teenagers with firstpresentation borderline personality disorder. Psychiatry Res 2008; 163 116-25.

44 Brunner R, Henze R, Parzer P, Kramer J, Feigl N, Lutz K, et al. Reduced prefrontal and orbitofrontal gray matter in female adolescents with borderline personality disorder: is it disorder specific? Neuroimage 2010; 49: $114-20$.

45 Goodman M, Hazlett EA, Avedon JB, Siever DR, Chu KW, New AS. Anterior cingulate volume reduction in adolescents with borderline personality disorder and co-morbid major depression. J Psychiatr Res 2011; 45: 803-7.

46 Whittle S, Chanen AM, Fornito A, McGorry PD, Pantelis C, Yucel M. Anterior cingulate volume in adolescents with first-presentation borderline personality disorder Psychiatry Res 2009; 172: 155-60.

47 Nunes PM, Wenzel A, Borges KT, Porto CR, Caminha RM, de Oliveira IR. Volumes of the hippocampus and amygdala in patients with borderline personality disorder: a meta-analysis. J Pers Disord 2009; 23: 333-45.

48 Zimmerman DJ, Choi-Kain LW. The hypothalamic-pituitary-adrenal axis in borderline personality disorder: a review. Harv Rev Psychiatry 2009; 17: 167-83.

49 Nater UM, Bohus M, Abbruzzese E, Ditzen B, Gaab J, Kleindienst N, et al. Increased psychological and attenuated cortisol and alpha-amylase responses to acute psychosocial stress in female patients with borderline personality disorder. Psychoneuroendocrinology 2010; 35: 1565-72.

50 Kaess $\mathrm{M}$, Hille M, Parzer $\mathrm{P}$, Maser-Gluth $\mathrm{C}$, Resch F, Brunner R. Alterations in the neuroendocrinological stress response to acute psychosocial stress in adolescents engaging in nonsuicidal self-injury. Psychoneuroendocrinology 2012; 37: 157-61.

51 Jovev M, Garner B, Phillips L, Velakoulis D, Wood SJ, Jackson HJ, et al. An MRI study of pituitary volume and parasuicidal behavior in teenagers with first-presentation borderline personality disorder. Psychiatry Res 2008; 163: 273-7.

52 Von Ceumern-Lindenstjerna IA, Brunner R, Parzer $\mathrm{P}$, Mundt C, Fiedler $\mathrm{P}$, Resch $F$. Initial orienting to emotional faces in female adolescents with borderline personality disorder. Psychopathology 2010; 43: 79-87.

53 Von Ceumern-Lindenstjerna IA, Brunner R, Parzer P, Mundt C, Fiedler P, Resch F. Attentional bias in later stages of emotional information processing in female adolescents with borderline personality disorder. Psychopathology 2010; 43: 25-32.

54 Jovev M, Chanen AM, Green M, Cotton SM, Proffitt T, Coltheart M, et al. Emotional sensitivity in youth with borderline personality pathology. Psychiatry Res 2011; 187: 234-40.

55 Jennings $\mathrm{T}$, Hulbert $\mathrm{C}$, Jackson $\mathrm{H}$, Chanen A. Social perspective coordination in youth with borderline personality pathology. J Pers Disord 2012; 26: 128-42.

56 Sharp C, Pane H, Ha C, Venta A, Patel AB, Sturek J, et al. Theory of mind and emotion regulation difficulties in adolescents with borderline traits. J Am Acad Child Adolesc Psychiatry 2011; 50: 563-73. 
57 Lawrence KA, Allen JS, Chanen AM. Impulsivity in borderline personality disorder: reward-based decision-making and its relationship to emotiona distress. J Pers Disord 2010; 24: 786-99.

58 Afifi TO, Mather A, Boman J, Fleisher W, Enns MW, Macmillan $\mathrm{H}$ et al. Childhood adversity and personality disorders: results from a nationally representative population-based study. J Psychiatr Res 2011; 45: 814-22.

59 Bradley R, Jenei J, Westen D. Etiology of borderline personality disorder: disentangling the contributions of intercorrelated antecedents. J Nerv Ment Dis 2005; 193: 24-31.

60 Cohen P. Child development and personality disorder. Psychiatr Clin North Am 2008; 31: 477-93.

61 Johnson JG, Cohen P, Brown J, Smailes E, Bernstein DP. Childhood maltreatment increases risk for personality disorders during early adulthood. Arch Gen Psychiatry 1999; 56: 600-6.

62 Cohen $\mathrm{P}$, Chen $\mathrm{H}$, Gordon $\mathrm{K}$, Johnson J, Brook J, Kasen S. Socioeconomic background and the developmental course of schizotypal and borderline personality disorder symptoms. Dev Psychopathol 2008; 20: 633-50.

63 Bezirganian S, Cohen P, Brook JS. The impact of mother-child interaction on the development of borderline personality disorder. Am J Psychiatry 1993; 150: $1836-42$.

64 Johnson JG, Cohen $\mathrm{P}$, Chen $\mathrm{H}$, Kasen S, Brook JS. Parenting behaviors associated with risk for offspring personality disorder during adulthood. Arch Gen Psychiatry 2006; 63: 579-87.

65 Crawford TN, Cohen PR, Chen H, Anglin DM, Ehrensaft M. Early maternal separation and the trajectory of borderline personality disorder symptoms. Dev Psychopathol 2009; 21: 1013-30.

66 Carlson EA, Egeland B, Sroufe LA. A prospective investigation of the development of borderline personality symptoms. Dev Psychopathol 2009; 21: 1311-34.

67 Kraemer HC, Kazdin AE, Offord DR, Kessler RC, Jensen PS, Kupfer DJ. Coming to terms with the terms of risk. Arch Gen Psychiatry 1997; 54: 337-43.

68 Eaton WW, Badawi M, Melton B. Prodromes and precursors: epidemiologic data for primary prevention of disorders with slow onset. Am J Psychiatry 1995; 152: 967-72.

69 Rohde P, Lewinsohn PM, Kahler CW, Seeley JR, Brown RA. Natural course of alcohol use disorders from adolescence to young adulthood. J Am Acad Child Adolesc Psychiatry 2001; 40: 83-90.

70 Thatcher DL, Cornelius JR, Clark DB. Adolescent alcohol use disorders predict adult borderline personality. Addict Behav 2005; 30: 1709-24.

71 Stepp SD, Burke JD, Hipwell AE, Loeber R. Trajectories of attention deficit hyperactivity disorder and oppositional defiant disorder symptoms as precursors of borderline personality disorder symptoms in adolescent girls. J Abnorm Child Psychol 2012; 40: 7-20.

72 Burke JD, Stepp SD. Adolescent disruptive behavior and borderline personality disorder symptoms in young adult men. I Abnorm Child Psychol 2012; 40: 35-44.

73 Zanarini MC, Frankenburg FR, Ridolfi ME, Jager-Hyman S, Hennen J, Gunderson JG. Reported childhood onset of self-mutilation among borderline patients. J Pers Disord 2006; 20: 9-15.

74 Nock MK. Self-injury. Annu Rev Clin Psychol 2010; 6: 339-63.

75 Brunner R, Parzer P, Haffner J, Steen R, Roos J, Klett M, et al. Prevalence and psychological correlates of occasional and repetitive deliberate self-harm in adolescents. Arch Pediatr Adolesc Med 2007; 161: 641-9.

76 Nock MK, Joiner JTE, Gordon KH, Lloyd-Richardson E, Prinstein MJ. Non-suicidal self-injury among adolescents: diagnostic correlates and relation to suicide attempts. Psychiatry Res 2006; 144: 65-72.
77 Muehlenkamp JJ, Ertelt TW, Miller AL, Claes L. Borderline personality symptoms differentiate non-suicidal and suicidal self-injury in ethnically diverse adolescent outpatients. J Child Psychol Psychiatry 2011; 52: 148-55.

78 Jacobson CM, Muehlenkamp JJ, Miller AL, Turner JB. Psychiatric impairment among adolescents engaging in different types of deliberate self-harm. J Clin Child Adolesc Psychol 2008; 37: 363-75.

79 Stepp SD, Pilkonis PA, Hipwell AE, Loeber R, Stouthamer-Loeber M. Stability of borderline personality disorder features in girls. J Personal Disord 2010; 24: $460-72$

80 Crick NR, Murray-Close D, Woods K. Borderline personality features in childhood: a short-term longitudinal study. Dev Psychopathol 2005; 17 1051-70.

81 Cohen P. Childhood risks for young adult symptoms of personality disorder: method and substance. Multivar Behav Res 1996; 31: 121-48.

82 Bernstein DP, cohen P, Skodol A, Bezirganian S, Brook J. Childhood antecedents of adolescent personality disorders. Am J Psychiatry 1996; 153: 907-13.

83 Kasen S, Cohen P, Skodol AE, Johnson JG, Brook JS. Influence of child and adolescent psychiatric disorders on young adult personality disorder. Am J Psychiatry 1999; 156: 1529-35.

84 Crawford TN, Cohen P, Johnson JG, Kasen S, First MB, Gordon K, et al. Self-reported personality disorder in the Children in the Community Sample: convergent and prospective validity in late adolescence and adulthood. $J$ Pers Disord 2005; 19: 30-52.

85 Cicchetti D, Toth SL. The past achievements and future promises of developmental psychopathology: the coming of age of a discipline. J Child Psychol Psychiatry 2009; 50: 16-25.

86 Cuijpers P. Examining the effects of prevention programs on the incidence of new cases of mental disorders: the lack of statistical power. Am J Psychiatry 2003; 160: 1385-91.

87 Chanen AM, McCutcheon L, Germano D, Nistico H, Jackson HJ, McGorry PD. The HYPE Clinic: an early intervention service for borderline personality disorder. J Psychiatr Pract 2009; 15: 163-72.

88 Ryle A, Kerr IB. Introducing Cognitive Analytic Therapy. Wiley, 2002.

89 Blum N, St John D, Pfohl B, Stuart S, McCormick B, Allen J, et al. Systems Training for Emotional Predictability and Problem Solving (STEPPS) for outpatients with borderline personality disorder: a randomized controlled trial and 1-year follow-up. Am J Psychiatry 2008; 165: 468-78.

90 Chanen AM, Jackson HJ, McCutcheon L, Dudgeon P, Jovev M, Yuen HP, et al. Early intervention for adolescents with borderline personality disorder: a quasi-experimental comparison with treatment as usual. Aust $N \mathrm{Z} J$ Psychiatry 2009; 43: 397-408.

91 Aviram RB, Brodsky BS, Stanley B. Borderline personality disorder, stigma, and treatment implications. Harv Rev Psychiatry 2006; 14: 249-56.

92 Rusch N, Holzer A, Hermann C, Schramm E, Jacob GA, Bohus M, et al. Self-stigma in women with borderline personality disorder and women with social phobia. J Nerv Ment Dis 2006; 194: 766-73.

93 Skodol AE, Bender DS, Morey LC, Clark LA, Oldham JM, Alarcon RD, et al. Personality disorder types proposed for DSM-5. J Pers Disord 2011; 25 136-69.

94 Tyrer P, Crawford M, Mulder R, Blashfield R, Farnam A, Fossati A, et al. The rationale for the reclassification of personality disorder in the 11th revision of the International Classification of Diseases (ICD-11). Personal Ment Health 2011; 5: 246-59.

95 McGorry PD. Risk syndromes, clinical staging and DSM V: new diagnostic infrastructure for early intervention in psychiatry. Schizophr Res 2010; 120 $49-53$. 